\title{
The Challenges in Product Design and Development in Project Management towards IR4.0
}

\author{
M.H. Othman ${ }^{1 *}$, Mohammed Bamasood ${ }^{1}$ \\ ${ }^{1}$ Faculty of Mechanical Engineering and Manufacturing (FKMP), \\ Universiti Tun Hussein Onn Malaysia, Johor, 86400, Parit Raja, Batu Pahat, Johor, MALAYSIA \\ *Corresponding Author
}

DOI: https://doi.org/10.30880/jamea.2021.02.01.004

Received 15 March 2021; Accepted 13 June 2021; Available online 02 August 2021

\begin{abstract}
This paper provides a review about the challenges in product design and development (PDD) in the context of the Industrial Revolution 4.0 (IR 4.0), with a particular focused on the problems that may be encountered by the project management (PM) team in the PDD phase. In recent decades, there has been a large number research, design, and development studies related to IR 4.0, such as synthesizing the applications of Big Data, Internet of things (IoT), Cloud Computing, Cybersecurity, and Artificial Intelligence. The effect of this revolution in technology is changing rapidly with new models and methods of manufacturing that have been proposed for the new future. The pandemic Covid-19 also accelerates the interest in using all kinds of online technology. However, to adapt and achieve the benefits of this revolution, industry players have to encounter several issues related to the PM, especially during the PDD phase. The management challenges discussed in this study were divided into four categories: the project team member selection, team leader selection, identifying potential customers, and design for the environment. In addition, some of the solutions and recommendation has been described using several examples.
\end{abstract}

Keywords: Product design and development, project management, industrial revolution 4.0, project team members, team leader, potential customer and design for environment

\section{Introduction}

The competition between the industries to produce a new product that satisfies customer demands is rising each year, which sparked the attention of industries in the product design and development area to develop new products that suit customer needs [1]. Product design and development (PDD) play an important role in achieving a competitive edge and success in new product development. The product design and development faced a lot of challenges in the global market, to make the PDD become more efficient and effective for better products [2]. The challenges increase with the demand for applications in line with the requirement of Industrial Revolution 4.0 (IR.4.0).

PDD had been considered as the primary stage of the company's growth. PDD is connected with the innovation especially related to IR4.0, to increase competition among the companies and the number of potential customers. The PDD-IR4.0 can produce a valuable product by using creative ideas for the successful launch of the product by meeting the customers and transfer the voice of the customer into the product, with efficient project management. It provides the ability to market the products on the global market. However, some products are not suited for the global market and must be re-evaluated during the PDD. It is because the new and innovative products with an adaptation of IR4.0 can be easily marketed in the industrialized countries while sales in the developed countries are lower. The main reasons were the high price of the products and lower income of the customers in the developed countries [3]. During the PDD, the most critical decisions are made, including cost, appearance, materials selection, innovation, performance, sustainability, and quality, which will affect the final product and its market [4]. PDD team should determine the customer needs and requirements (voice of customer) and transfer it into a valuable product that meets these needs. In addition, the PDD team 
needs to determine how to proceed with a design concept and make choices according to the risks and benefits, by applying the essence of IR4.0 [5]. By embracing the benefits of IR4.0 technologies, the PDD team should also consider the sustainability aspect throughout product design by utilizing the reuse, recycle and re-manufacturing concepts to create a closed-loop product life-cycle [6].

\section{Industrial Revolution 4.0}

IR.4.0 has fascinated the responsiveness of manufacturing sectors over the past decades. Despite numerous knowledge transfer from research activities to practical application, implementing IR4.0 ideas poses significant hurdles for companies, particularly during the PPD phase. Some industries do not understand the revolution or procedures in place to prepare for it, as well as a lack of attention to adapt to massive changes in concept and technology [18]. Individual practises, work practises, business practises, and industry structures, for example, might all be affected by a digital disruption in IR 4.0. This disruption may affect businesses if they do not raise awareness of the effects of IR 4.0 [19].

However, becoming more familiar with IR 4.0 could provide more perspective and benefits to PDD by making it more competitive, as many manufacturing sectors are eager to accept the concept of this revolution [20]. The main challenge in implementing IR4.0 was a lack of specific instruments and information about the components of IR4.0 [20,21]. To address this issue, a few assessment models illustrating the advantages of adapting to this revolution have been developed, as opposed to the traditional PDD technique without IR4.0 elements. It provides a comprehensive impression of the novel concepts and easiness to cuddle with. The development of a web-based version of the assessment model and its dissemination in manufacturing industries also had been proposed, to allow the recognition of the industry competitive situation and understanding the implementation of IR.4.0 as well as its development over time, especially during PDD [18].

\section{Challenges and Problems}

PDD projects are confronted with challenges and issues that may limit their chances of success or create an unfavourable atmosphere for project teamwork, making IR4.0 adaptation even more crucial. Some obstacles will be discussed in this section based on project team member selection, team leader selection, identifying potential customers, and environmental design (DFE). The need of connecting these project management difficulties in PDD to IR4.0 adaptation has been stressed. The connecting of these project management issues in PDD with the adaptation of IR4.0 will be emphasized.

\subsection{Project Team Member Selection}

The PDD projects are completed by working as a team because it's not possible to finish the work individually on time or by individuals working sequentially. The working team is an essential component of any successful project, and team members should be chosen based on their abilities and expertise. For the PDD initiative to succeed, finding the appropriate individual in the right position is a challenge [15]. Researchers discovered that team members that work together for a long time have better outcomes than new team members [7]. This is because team members grow awareness of each other's knowledge. However, the researchers discovered that project team members who have worked together for over three years have a negative influence on the PDD due to decreasing communication with the world outside the project group, which leads to more conversation about less relevant problems. As a result, there is a curvilinear relationship between team stability and PDD performance, with performance improving at first and then declining as team stability grows [16].

Therefore, some companies used temporary project-based teams to gain more products and increase project success. It provides the potential of the highest level of expertise to every each project. The temporariness of these project-based teams means that team member familiarity and understanding derived from team longevity are absent [7]. These temporary teams should have a high adaptation of IR4.0 elements, for instance, the IR 4.0 could have used smart robots and substitute humans in certain job sectors and industries. However, specific skills, knowledge, and emotional intelligence can never be replaced by robots. Because of the technological advancement, the related sector needs to focus on training on innovation and adaptability, rather than the conventional methods [26]. Some examples for a design project that is related to IR4.0 are the Portable Industrial Automation Education Training Kit [25] and Gamification Framework Design of Management Education and Development [26]. Based on these projects, it is necessary to ensure that the new design meets the requirement of revolution elements, as well as to assist teaching and learning in many applications for IR 4.0 [26].

It is critical to develop good PDD and project management team members that understand the concept of IR 4.0. However, the labor provider seems to be not adjusting fast enough to respond to particular skills and knowledge such as cybersecurity, Internet of Things (IoT), Big Data, Cloud Computing and Artificial Intelligence. These skills and expertises are needed because of the nature of IR4.0, where all devices technologies are interconnected, exchanging data and information with each other. Furthermore, rising disruptive technologies that drive new business models provide challenges to the industries sector, such as ambiguous economic advantages, excessive investment, insufficient staff 
skills, a lack of stakeholders support, and a delayed expansion of critical infrastructure. All these issues and challenges will affect the generation of human capital for manufacturing industries related to IR4.0 [22].

According to Tan and Tang [23], most of the occupations that would have the highest demand for high-skill employment in recent economies environment might grow. Hence, the higher education institution that supplies the future workers should exploit the potential opportunities brought by the IR4.0 with much responsibility and wisdom, by providing digital leadership for their institutions. The technical and vocational institution also should be able to answer what are the key features of a future-ready education ecosystem and what are the key adaptation strategies for managing the transition to a new world of work in IR4.0 transformation to ensure the ideal workers for the future is personnel who can work in a fully physical or data automation integrated with the latest technology enhanced- environment. They should understand the new term in modern workplace such as the Internet of Things system and be able to solve the problems when they are arising in the production or manufacturing lines. Finally, the employer should aware and responsible to their work to fulfill the need and demand from the industries for future knowledge and technical \& vocational competencies [24].

The further review had mentioned the priorities of selecting team members that are aware of IR4.0. To drive mass production in intelligent industries, machines and products are going to be communicated with each other. Intelligent factories will be the next future of existing industries, where raw resources and machines are interconnected through the Internet of Things technology. Therefore, a skilled man workforce will be required in high demand because when the intelligent machine will replace the man workforce then to monitor and manage the complexities with intelligent machine skilled workers are required. The structure of existing education systems needs to be upgraded to cope with challenges that arisen because of IR 4.0 affected employability potentials and mass production in manufacturing industries. For example, the cyber-physical system where all machines and materials will be connected in such a way that they can communicate with each other cooperatively through intelligent sensors and communication technology. Hence the exiting education needs to learn about these matters [28].

Based on the previous findings, for IR4.0 adaptation, there are three important technical skill themes which were analyzing, interpreting, and documenting data; understanding and optimizing process; and executing, troubleshooting, and maintaining of devices. Based on the conclusion, the researchers have found that the respondents' level of knowledge and skills to most of the technical competency is still at the average level and demand more attention. The findings were in line with Flynn, Dance, and Schaefer [39], which mentioned the weakness of higher education in responding to changes signals and moderately responsive to long-term trends. To solve this problem, new technical information related to IR4.0 should be embedded in the new curriculum for their future knowledge, to fit with the need for changes in the IR4.0 era [38].

\subsection{Team Leader Selection}

Leader behaviours can improve or hinder project effectiveness in any collaborative environment. The importance of collaboration behaviour for project success has far-reaching implications for leadership. The project leader is a key character who can influence the performance of other team members and the PDD project's process, as well as keep teams motivated and focused. Because this work will be done as a team, determining who will be the team leader is a tough and important factor for the success of any PDD project [8]. The challenge becomes more critical when the leader must have prior knowledge and experience, which is related to IR4.0.

The team leader is a key part of the project collaboration; he is the team's engine; a competent team leader who can handle all the team members' tasks may improve the project's effectiveness for the company or industry. Collaborative behaviors in project teams are unusual unless team leaders take specific actions to foster an environment of trust, creativity, and collaboration, according to the researchers. According to several experts, the team leader is a key member who motivates the other team members to perform their responsibilities correctly and on time. The team leader is the driving factor that brings project participants together to guarantee an unified effort in adapting to IR.4.0 technologies [8].

Because the PDD project cannot be completed individually, the team leader must be able to persuade the team members to employ IR4.0 technologies to produce collaborative action in the project. Furthermore, the team leader must be a problem solver, as the PDD project will encounter many problems as it progresses to completion, and the leader must be flexible and capable of dealing with each situation perfectly and competently. Overall, the team leader's character and leadership qualities will have a significant impact on the work performance and quality [17].

Solving the leadership issues related to IR4.0 had been addressed in [27], whereby leaders from the management team need to make a decision that portrays influences on many issues such as technology, data management and analytics, data security, risk management, regulatory compliance, validation, and human resource practices. More issues related to changes of technologies such as submission of artificial intelligence, sensors, enterprise-level solution platforms, and machine learning will be perplexing. When using the components of IR4.0, for example, the volume of external and internal IoT data will expand, requiring additional information transformation. The massive flow of data to quality professionals in real-time, which will come from multiple sources, will cause the intelligence of current management for rapid and efficient decision-making, just as the quality assurance department must ensure effective implementation of Quality 4.0 or EQMS 4 to meet the IR4.0 requirements [27]. 


\subsection{Identifying Potential Customers}

Understanding the demographic features of the product consumer to enhance and develop the product market and find new customers is one difficulty in the PDD project. Because of the poorer understanding of the demands and identifying possible clients of this product, this problem may cause a new product that does not satisfy the exact customer needs.

A thorough grasp of the product market enables a firm to develop new goods that address a greater variety of market and consumer demands [14]. Not only that, but the IR4.0 component will assist the PDD in its hunt for new clients.

Technology has been the driving force behind advancement in nearly every field. Evolving technologies are bringing forth major changes that are changing the manufacturing sectors [29]. Information technology allows businesses to retain extensive records of their customers' business interactions, allowing them to better understand their demands. These data can be used to conduct marketing research during the new PDD to better understand potential customers and save time by using data that has been stored previously or obtained from another company rather than conducting interviews and surveys, which may reduce the accuracy of the data because of unrealistic data provided by some customers [9]. When potential customers demand that manufacturing companies adapt to IR4.0's needs, the problem becomes much more difficult.

It was found that recognizing and evaluating the effects and challenges of IR 4.0, especially the digitalization of the production processes was vital to the industries. Previous researchers have stated that customers with IR4.0 background will face information technology security issues, reliability and stability of machine-to-machine communication. More solutions for short yet consistent latency of manufacturing processes will be demanded by IR4.0 customers. The lack of appropriate skill sets linked to IR 4.0 is also seen as an issue that should be addressed when new sectors are transformed [40]. According to some findings, the most difficult aspect of implementing IR 4.0 is the customer's concern about information technology security risk, because most of the integration among various entities in IR 4.0 is done online, exposing the customer to security breaches and data leaks to cyber theft. As a result, internet security is a critical problem that the PPD project team must address [41].

\subsection{Design for Environment}

Design for the Environment (DFE) refers to the process of designing and developing a product with environmental considerations in mind, i.e., reducing the product's environmental effect in order to attain sustainability. Because of global warming and carbon emissions, the DFE is becoming an increasingly significant component of each new PDD project. As a result, the DFE views the PDD as a challenge [13]. During the PDD stage, DFE considers the influence of this product or process on the environment in order to create a product that is low impact and ecologically friendly. In other words, decreasing material and energy consumption, lowering process waste by producing more commodities, and optimising reuse and recycling opportunities [11].

A systematic strategy for attaining the DFE has been proposed and explored by several researchers. The first stage is problem formulation, which involves outlining the company strategy and the stakeholders who make up the strategy in order to create a basis for using a systematic evaluation process. The second stage of the technique involves applying quantitative analysis to evaluate the company strategy while considering the environmental impact of product quality and cost performance. A framework for integrating environmental and business aspects of sustainable product creation has been created by a growing number of researchers. Before multi-criteria decision-making, the life-cycle assessment is performed to evaluate the supplied environmental aspects, and the results are then utilized to select DfE methods [12].

Design is crucial in a manufacturing process as it reflects the intellectual and technical capabilities of a PDD project teams to fulfill the user or customer. A review had been conducted on the various challenges and failures that the designer faces in PDD, especially adapting to the environment of IR4.0 [30]. Before commencing the design, the flow of operations must be determined, as this will define the process flow and reduce the time required to complete the product. Using IR4.0 technology will help to shorten the time to complete the whole design and implementation. A good design depends on sound planning and a management team that understands how to use IR4.0 technology. In managing product design, project management principles with IR.4.0 essence are critical. The product designer's job in PDD is to employ IR4.0 technology to discover where the design flaw is without having to wait for damage, physical harm, or death to occur. Manufacturers would conduct stringent quality checks using IR4.0-related automation and quality control methods at each level of production [31]. According to a review by Fotouhi and Sorooshian [31], IR 4.0 is deeply interconnected with product designs through existing online information, and by adapting to these phenomena, genuine and high-quality products can be designed and produced with lower costs, faster delivery, and greater manufacturing flexibility [32]. Increased efficiency and productivity [33,34,35], cheaper costs [35], enhanced product quality [36], increased customer satisfaction [33, 34, 37, 38], rapid innovation [35], and increased revenues [37] are among the benefits of IR.4.0. As a result, the environment's design must be compatible with the use of IR4.0 technology.

\section{Summary}

There are many challenges that PDD and project management may face in the IR4.0 era that have an impact on the final product. This paper focuses on four critical challenges which are project team member selection, team leader 
selection, identifying potential customer, and design for environment (DFE) related to the adaption of IR4.0. Because of the function of each member of the project team, selecting project team members who are well versed and trained in IR4.0 technology has been a challenge for the organisation. Putting the correct skills or person in the proper place is a challenge for the company. Team leaders who are knowledgeable about IR4.0 elements play a key role in uniting the team around a common purpose and target, as well as decreasing work time by distributing responsibilities among team members and motivating them. After converting the voice of the client's demands for products, identifying the prospective consumer is the key to a successful product that fulfills all the needs and requirements related to IR4.0. Identifying the potential customer is the key to a successful product where meets all the needs and requirements related to IR4.0 after transferring the voice of the customer's needs into the products. The adaptation of Design for Environment (DFE) with IR4.0 is one of the most essential challenges affecting our environment in order to lessen our carbon footprint. This is to ensure that the next generation of humans can meet their own requirements and surviving in this planet.

\section{Acknowledgment}

This work was supported by the Faculty of Mechanical and Manufacturing Engineering, UTHM, and the Ministry of Higher Education Malaysia for the Fundamental Research Grant Scheme (K196). The authors would like to express their gratitude to those who are directly or indirectly involved with the completion of this review paper.

\section{References}

[1] O.P, Yadav, B.P. Nepal, and R. Jain, "Managing product development process complexity and challenges: a state-of-the art review," Journal of Design Research, vol. 6, no. 4, pp.487-508, 2007

[2] O. P. Yadav and N. Singh, "Perspectives and challenges for product reliability assurance in the product development process". International Journal of Product Development, vol.5 no.1-2, pp 4-16, 2008

[3] M. Chandra, and J.P. Neelankavil, "Product development and innovation for developing countries: potential and challenges," Journal of Management Development, vol.27, no.10, pp.1017-1025, 2008

[4] T. Bhamra and V. Lofthouse, "Design for sustainability: A practical approach," Gower Publishing, Ltd, pp. 37 38,2007

[5] G. Howarth, and M. Hadfield, “A sustainable product design model” Materials and Design, vol. 27, pp.11281133,2006

[6] L. G. Curwen, J. Park, and A. K. Sarkar, "Challenges and solutions of sustainable apparel product development: A case study of Eileen Fisher," Clothing and Textiles Research Journal, vol. 31, no.1, pp. 32-47, 2013

[7] A.C. Edmondson, and I.M. Nembhard, "Product development and learning in project teams: The challenges are the benefits," Journal of Product Innovation Management, vol. 26, no.2, pp. 123-138, 2009

[8] Z. H. Aronson, R. R. Reilly, and G. S. Lynn, "The impact of leader personality on new product development teamwork and performance: The moderating role of uncertainty," Journal of Engineering and Technology Management, vol. 23, no.3, pp. 221-247, 2006

[9] P. B. Chou, E. Grossman, D. Gunopulos, and P. Kamesam, "Identifying prospective customers," In Proceedings of the sixth ACM SIGKDD international conference on Knowledge discovery and data mining, pp. 447-456, 2000

[10] S. Liu and I. M. Boyle, "Engineering design: perspectives, challenges, and recent advances," Journal of Engineering Design, vol.20, no.1, pp. 7-19, 2009

[11] C. Chen, "Design for the environment: A quality-based model for green product development," Management Science, vol.47, no.2, pp. 250-26, 2001

[12] C.Vezzoli, F. Ceschin, J.C. Diehl, and C. Kohtala, "New design challenges to widely implement 'Sustainable Product-Service Systems'," Journal of Cleaner Production, vol. 97, pp.1-12. 2015

[13] H.Metta, and F. Badurdeen, "Integrating sustainable product and supply chain design: modeling issues and challenges,” IEEE Transactions on Engineering Management, vol. 60, no.2, pp. 438-446, 2012

[14] O. Isaksson, T.C. Larsson, and A. Ö. Rönnbäck, "Development of product-service systems: challenges and opportunities for the manufacturing firm," Journal of Engineering Design, vol.20, no.4, pp. 329-348, 2009.

[15] R. R Reilly, G. S Lynn, and Z. H. Aronson, "The role of personality in new product development team performance," Journal of Engineering and Technology Management, vol.19, no.1, pp. 39-58, 2002

[16] A. E.Akgün, M. Dayan, and A.Di Benedetto, "New product development team intelligence: Antecedents and consequences," Information and Management, vol.45, no. 4, pp. 221-226, 2008

[17] S. Sarin and C. McDermott, "The effect of team leader characteristics on learning, knowledge application, and performance of cross-functional new product development teams," Decision sciences, vol. 34, no. 4, pp. 707 739,2003

[18] Selamat, A., Alias, R.A., Hikmi, S.N., Puteh, M. and Tapsi, S.M., Higher education 4.0: Current status and readiness in meeting the fourth industrial revolution challenges. Redesigning Higher Education towards Industry, 4, pp.23-24, 2017 
[19] E. Rauch, T. Stecher, M. Unterhofer, P. Dallasega, D.T.Matt, "Suitability of IR4.0 Concepts for Small and Medium Sized Enterprises: Comparison between an Expert Survey and a User Survey". In Proceedings of the International Conference on Industrial Engineering and Operations Management, Bangkok, Thailand, 2019

[20] P. Saxena, M. Papanikolaou, E. Pagone, K. Salonitis, M.R. Jolly, "Digital Manufacturing for Foundries 4.0". In Light Metals 2020; Springer: Cham, Switzerland, pp. 1019-1025, 2020

[21] D.T. Matt, E. Rauch, "SME 4.0: The Role of Small-and Medium-Sized Enterprises in the Digital Transformation" In IR4.0 for SMEs; Palgrave Macmillan: Cham, Switzerland, pp. 3-36, 2020

[22] R.Hassan and A.A. Ismail, "Challenge and Issue in Human Capital Development Towards Industry Revolution 4.0" Proceedings of International Conference on The Future of Education IConFEd) 2018, Institute of Teacher Education Tuanku Bainun Campus, Penang, Malaysia, 10-12 July 2018

[23] K.S. Tan, K.S. and J.T. Tang, "New skills at work: Managing skills challenges in ASEAN-5", 2016

[24] Selamat, R.A. Alias, S.N. Hikmi, M. Puteh, S.M. Tapsi, "Higher education 4.0: Current status and readiness in meeting the fourth industrial revolution challenges". Redesigning Higher Education towards Industry, 4, pp.2324,2017

[25] A.R.M. Khairudin, N.A.S.Aziz, M.A. F.M. Azlan, M.H.A Karim, \& N.M. Zian, "Design of Portable Industrial Automation Education Training Kit Compatible for IR 4.0”. In 2019 IEEE 7th Conference on Systems, Process and Control (ICSPC) pp. 38-42, 2019

[26] Rahardja, U., Aini, Q., Graha, Y. I., \& Tangkaw, M. R. (2019, December). Gamification Framework Design of Management Education and Development in Industrial Revolution 4.0. In Journal of Physics: Conference Series (Vol. 1364, No. 1, p. 012035). IOP Publishing

[27] B. Mohamed, S. Ismail, and D. Abdullah, "Industrial Revolution (IR4.0) Impact on Management", In Proceedings of the International Conference on Creative Economics, Tourism and Information Management (ICCETIM 2019) - Creativity and Innovation Developments for Global Competitiveness and Sustainability, pp. 104-109, 2019

[28] G. Tilak, \& D. Singh, "IR4.0-4th Rising Industrial Revolution in Manufacturing Industries and its Impact on Employability and Existing Education System”, Pramana Research Journal, Vol. 8, No.11, pp. 161-169, 2018.

[29] J.G. Harry, "The New Technologies: An Industrial Revolution", Journal of Business Strategy, Vol. 5, No. 2, pp.83-85, 1984

[30] B, Pratima \& B. Nilima "Product Design: Challenges and Evaluation" IOSR Journal of Electronics and Communication Engineering, Vol. 9, No. 4, pp.26-28, 2014

[31] N. Fotouhi, \& S. Sorooshian, "Review of IR4.0 with focus on products". In IOP Conference Series: Earth and Environmental Science, IOP Publishing, Vol. 442, No. 1, pp. 012011, 2020

[32] F. Almada-Lobo, "Six benefits of IR4.0 for businesses" Control Engineering, 2017

[33] M. Rüßmann, M.Lorenz, P.Gerbert, M, Waldner, J. Justus, P. Engel, \& M. Harnisch, "IR4.0: The future of productivity and growth in manufacturing industries". Boston Consulting Group, Vol. 9No. 1, pp. 54-89. 2015

[34] S.LLC. "Simio's 8 Reasons to Adopt IR4.0", Retrieved from https://www.prnewswire.com/news-releases/simios8-reasons-to-adopt-industry-4-0--300629039.html, 2018

[35] L.K. Narayan, “Computer Aided Design and Manufacturing” New Delhi: Prentice Hall of India, 2008

[36] L. Martin, "IR4.0: Definition, Design Principles Challenges, and the Future of Employment" Retrieved from https://www.cleverism.com/industry-4-0/, 2019

[37] R. Burke, A, Mussomeli, S. Laaper, M. Hartigan and B, Sniderman, "The smart factory" https://www2.deloitte.com/insights/us/en/focus/industry-4-0/smart-factoryconnectedmanufacturing. html. 2017

[38] A.A. Ismail, \& R. Hassan, "Technical Competencies in Digital Technology towards Industrial Revolution 4.0." Journal of Technical Education and Training, Vol.11, No. 3, 2019

[39] J. Flynn, S.Dance, \& D. Schaefer, "IR4.0 and its Potential Impact on Employment Demographics in the UK." Advances in Transdisciplinary Engineering, Vol. 6, pp 239-44, 2017

[40] R.C.Schlaepfer, M.Koch, \& P. Merkofer, "IR4.0. Challenges and Solutions for the Digital Transformation and Use of Exponential Technologies”. Deloitte, pp.1-30. 2015

[41] J. Sung, "The fourth industrial revolution and precision agriculture. Automation in Agriculture: Securing Food Supplies for Future Generations", 1.2018 